Research article Open Access

\title{
Osteopontin is a potential target gene in mouse mammary cancer chemoprevention by Se-methylselenocysteine
}

\author{
Emmanual Unni, Frances S Kittrell, Uma Singh and Raghu Sinha
}

\author{
Department of Molecular and Cellular Biology, Baylor College of Medicine, Houston, Texas, USA \\ Corresponding author: Raghu Sinha, rsinha@ifcp.us
}

Received: 15 Mar 2004 Revisions requested: 30 Apr 2004 Revisions received: 14 Jun 2004 Accepted: 24 Jun 2004 Published: 29 Jul 2004

Breast Cancer Res 2004, 6:R586-R592 (DOI 10.1186/bcr914)

(C) 2004 Unni et al.; licensee BioMed Central Ltd. This is an Open Access article: verbatim copying and redistribution of this article are permitted in all media for any purpose, provided this notice is preserved along with the article's original URL.

\begin{abstract}
Background Se-methylselenocysteine (MSC) is a naturally occurring organoselenium compound that inhibits mammary tumorigenesis in laboratory animals and in cell culture models. Previously we have documented that MSC inhibits DNA synthesis, total protein kinase $\mathrm{C}$ and cyclin-dependent kinase 2 kinase activities, leading to prolonged S-phase arrest and elevation of growth-arrested DNA damage genes, followed by caspase activation and apoptosis in a synchronized TM6 mouse mammary tumor model. The aim of the present study was to examine the efficacy of MSC against TM6 mouse mammary hyperplastic outgrowth (TM6-HOG) and to determine in vivo targets of MSC in this model system.

Methods Twenty mammary fat pads each from female Balb/c mice transplanted with TM6-HOG and fed with $0.1 \mathrm{ppm}$ selenium and with $3 \mathrm{ppm}$ selenium respectively, were evaluated at 4 and 12 weeks after transplantation for growth spread, proliferative index and caspase-3 activity. Thirteen mice transplanted with TM6-HOG in each selenium group were observed for tumor formation over 23 weeks. Tumors from mice in both groups were compared by cDNA array analysis and data were confirmed by reverse transcription-polymerase chain reaction. To determine the effect of MSC on the expression of
\end{abstract}

the novel target gene and on cell migration, experiments were performed in triplicate.

Results A dietary dose of 3 ppm selenium significantly reduced the growth spread and induced caspase-3 activity in mammary fat pads in comparison with mice fed with the basal diet $(0.1$ ppm selenium). The extended administration ( 23 weeks) of 3 ppm selenium in the diet resulted in a tumor incidence of $77 \%$ in comparison with $100 \%$ tumor incidence in $0.1 \mathrm{ppm}$ seleniumfed animals. The size of TM6 tumors in the supplemented group was smaller (mean $0.69 \mathrm{~cm}^{2}$ ) than in the mice fed with the basal diet (mean $0.93 \mathrm{~cm}^{2}$ ). cDNA array analysis showed a reduced expression of osteopontin $(O P N)$ in mammary tumors of mice fed with the $3 \mathrm{ppm}$ selenium diet in comparison with OPN expression in tumors arising in $0.1 \mathrm{ppm}$ selenium-fed mice. A 24-hour treatment of TM6 cells with MSC significantly inhibited their migration and also reduced their OPN expression in comparison with untreated cells.

Conclusions OPN is a potential target gene in the inhibition of mammary tumorigenesis by selenium.

Keywords: cDNA array, cell migration, mouse mammary, osteopontin, Se-methylselenocysteine

\section{Introduction}

Se-methylselenocysteine (MSC) is a component of selenized brewer's yeast that has been successfully used to reduce overall cancer mortality by more than $40 \%$ in a human clinical intervention [1]. Specifically, this selenized yeast was composed of selenomethionine (more than $85 \%$ ), with components such as MSC, selenocystathione, selenocystine and other unidentified organic selenium compounds forming the remainder [2]. MSC suppresses carcinogen-induced mammary carcinogenesis in rat model
$[3,4]$, in which it enhances the fraction of p27Kip1-positive cells in mammary intraductal proliferations [5]. In vitro, MSC is an effective growth inhibitor of mammary cells $[6,7]$. We have shown in a synchronized TM6 mouse mammary tumor cell model that MSC inhibits DNA synthesis and total protein kinase $\mathrm{C}$ activity, causes $\mathrm{S}$-phase arrest of these cells, reduces cyclin-dependent kinase 2 kinase activity, and induces growth-arrested DNA damage genes $[7,8]$. In the same model system MSC also activated caspase-3 and induced apoptosis [9]. More recently, we have 
documented the inhibition of phosphatidylinositol 3-kinase activity followed by dephosphorylation of Akt by MSC in mouse mammary cells in vitro [10].

To identify potential targets of MSC in vivo, we used the cDNA array approach to compare gene expression profiles in the tumors arising from the mammary fat pads of mice fed on a diet high in selenium ( $3 \mathrm{ppm}$ Se as MSC) with those in tumors from mice fed on the basal diet $(0.1 \mathrm{ppm}$ Se as MSC). The differentially expressed genes included prothymosin $\alpha, Y B 1$ (Y box protein), the murine homologue of Drosophila single-minded gene ( $m$ Sim), apolipoprotein $E$, and osteopontin (OPN). Prothymosin $\alpha$ is an accepted marker of tumor prognosis [11]. $Y B 1$ is a key regulator for P-glycoprotein expression [12] and can predict drug resistance and patient outcome in breast cancer [13]. $\mathrm{mSim}$ is expressed in the ventral diencephalon, branchial arches, and limbs, and its function might assist in finding the cause of Down syndrome [14]. Apolipoprotein $E$ has an important role in lipid metabolism by serving as a ligand to hepatic lipoprotein receptors [15]. OPN is a secreted RGD (arginine-glycine-aspartic acid)-containing phosphoprotein that interacts with the $\alpha_{v} \beta_{3}$ integrin and is capable of promoting cell attachment, regulating intracellular $\mathrm{Ca}^{2+} \mathrm{lev}$ els, and influencing gene expression [16]. OPN is expressed at higher levels in various transformed cell lines than in their non-tumorigenic cell counterparts [17]. It has been associated with aggravated malignancy in breast cancer but its functional role in this context is poorly understood. In the present study we examined the efficacy of MSC against TM6 mouse hyperplastic outgrowth and the effect of MSC on the newly discovered in vivo target.

\section{Methods}

\section{TM6 hyperplasia model in Balb/c mice}

Twenty female Balb/c mice ( 3 weeks of age) were transplanted with TM6 hyperplastic outgrowth (TM6-HOG) in both cleared inguinal (no. 4) mammary fat pads [18]. Two weeks later, these mice were set up as two subgroups of 10 mice each and were fed on AIN-76A diet containing 0.1 ppm Se (nutritional level, basal diet) and $3 \mathrm{ppm}$ Se in the form of MSC $\left(\mathrm{CH}_{3}-\mathrm{Se}-\mathrm{CH}_{2}-\mathrm{CH}\left(\mathrm{NH}_{2}\right)-\mathrm{COOH}\right.$; Sigma, St Louis, MO). Mammary fat pads were collected 4 and 12 weeks after transplantation, and the whole mounts were examined for TM6-HOG growth spread. In addition, the proliferative index of the fat pads was assessed and apoptosis was measured by caspase-3 activity. To assess TM6induced tumor incidence, 26 female Balb/c mice were transplanted with TM6-HOG; 2 weeks later they were divided into two equal groups and fed on diets containing 0.1 and 3 ppm Se, respectively, as described above. The mice were palpated weekly for tumors for 23 weeks after transplantation. Some of these tumors were subjected to cDNA array analysis.

\section{Bromodeoxyuridine labeling and proliferative index}

Bromodeoxyuridine (BrdU; Sigma) was injected intraperitoneally into mice ( $70 \mathrm{mg}$ per $\mathrm{kg}$ body weight) 2 hours before being killed at 4 and 12 weeks after transplantation. The mammary fat pads were harvested, flattened, fixed in $4 \%$ paraformaldehyde for 1 hour, and post-fixed in $70 \%$ ethanol. Paraffin-embedded tissues were cut $(4-5 \mu \mathrm{m})$, then stained with hematoxylin-eosin for histology; sections were used for BrdU staining. The BrdU-labeling index for each group was determined [19] by immunohistochemistry with a cell proliferation kit (Amersham, Little Chalfont, UK). A total of 500 cells were counted for each mammary fat pad in each group and the proliferative index was calculated as the percentage of positive cells. A total of three fat pads were analyzed for each group at each time point.

\section{Colorimetric assay for caspase-3}

Mammary fat pads from each group of mice were homogenized in lysis buffer (10 mM Tris- $\mathrm{HCl}$ [pH 7.5], $200 \mathrm{mM}$ $\mathrm{NaCl}, 1 \%$ Triton X-100, $1 \mathrm{mM}$ oxidized glutathione, $5 \mathrm{mM}$ EDTA) on ice for $30 \mathrm{~min}$. Lysates were centrifuged at $10,000 \mathrm{rpm}(9300 \times \mathrm{g})$ for $10 \mathrm{~min}$ and the supernatant was used for the caspase-3 assay [9]. Four mammary fat pads were pooled for each group of the Se-fed animals 4 and 12 weeks after transplantation, and this assay too was performed in triplicate.

\section{CDNA array analysis}

TM6 tumor tissues from mice fed with 0.1 or $3 \mathrm{ppm}$ Se were compared for altered gene expressions after hybridization with individual membranes spotted with 1176 unique cDNA fragments (Atlas ${ }^{\mathrm{TM}}$ Mouse 1.2 Array; Clontech, Palo Alto, CA) as described previously [20]. After densitometric analysis (Molecular Dynamics, Sunnyvale, $\mathrm{CA})$ the signals were quantified and the values were normalized to ubiquitin (housekeeping gene) expression levels.

\section{Cell culture and treatment}

TM6 cells were grown in $100 \mathrm{~mm}$ dishes for 48 hours in Dulbecco's modified Eagle's medium (DMEM)/F12 medium supplemented with insulin $(5 \mu \mathrm{g} / \mathrm{ml})$, epidermal growth factor $(5 \mathrm{ng} / \mathrm{ml})$, adult bovine serum $(2 \%)$, and antibiotic-antimycotic solution $(1 \times)$ at $37^{\circ} \mathrm{C}$ in the presence of $5 \% \mathrm{CO}_{2}$ in air [8]. The cells were starved for 24 hours in $\mathrm{DMEM} / \mathrm{F} 12$ medium without growth factors and serum. The cells were then treated with MSC $(100 \mu \mathrm{M})$ for 1 hour or 24 hours in serum-free condition, followed by 1 hour of stimulation with growth factors and serum. RNAs from these cells were isolated by using TRIzol (Life Technologies, Gaithersburg, MD) and reverse transcriptionpolymerase chain reaction (RT-PCR) was performed for $O P N$ and $\beta$-actin as described below. 


\section{RT-PCR and probing}

Total RNAs from tumors of mice fed with 0.1 or 3 ppm Se diet, along with MSC-treated cells in vitro were isolated with the use of TRIzol. A 305 base pair PCR product for OPN was obtained with the forward primer 5'-CTT TCA CTC CAA TCG TCC CTA C-3' and the reverse primer 5'GCT CTC TTT GGA ATG CTC AAG T-3'. To normalize the expression of OPN, a 568 base pair PCR product for $\beta$ actin was generated from the same reverse transcription with the forward primer 5'-GAG AAG ATC TGG CAC CAC ACC T-3' and the reverse primer 5'-CAG GAT TCC ATA CCC AAG AAG G-3'. The PCR was performed in a PerkinElmer 9600 thermocycler after denaturation $\left(95^{\circ} \mathrm{C}\right.$ for 1 $\min 45 \mathrm{~s}), 26$ cycles of a three-step cycle $\left(95^{\circ} \mathrm{C}\right.$ for $15 \mathrm{~s}$, $57^{\circ} \mathrm{C}$ for $30 \mathrm{~s}$, and $72^{\circ} \mathrm{C}$ for $1 \mathrm{~min} 55 \mathrm{~s}$ ), and extension at $72^{\circ} \mathrm{C}$ for $10 \mathrm{~min}$. For hybridization, the OPN and $\beta$-actin PCR products were gel-purified with the Quiex II kit (Qiagen, Inc., Chatsworth, CA) and labeled with $[\alpha-32 P] d C T P$ with the Prime-a-gene kit (Promega, Madison, WI). The $\mathrm{PCR}$ reactions were run on agarose gels, transferred to a nylon membrane, and then hybridized with OPN probe, washed, and exposed to Kodak MS film for 2 hours. The same blot was subsequently probed with $\beta$-actin, washed, and exposed to Kodak MS film for 2 hours. The blots were scanned in a densitometer (Molecular Dynamics) and the values for OPN were normalized to the corresponding $\beta$ actin levels.

\section{Migration assay}

TM6 cells were grown for 48 hours in $100 \mathrm{~mm}$ Petri dishes in regular medium with growth factors and serum [8]. The cells were starved for 24 hours in DMEM/F12 medium without growth factors or serum. The cells were then treated with MSC $(100 \mu \mathrm{M})$ for 1 hour or 24 hours in serum-free condition. These pretreated cells were removed from each dish along with the untreated control cells, and
50,000 viable cells were transferred to $8 \mu \mathrm{m}$ pore size transwell chambers (Costar, Cambridge, MA), in triplicate. The chambers had previously been coated with gelatin $(6 \mathrm{mg} /$ $\mathrm{ml}$ ) on the inner side of the filters and rehydrated with 100 $\mu \mathrm{l}$ of DMEM/F12 medium. These chambers were placed in a 12-well plate. The cells were allowed to settle for 1 hour and the growth medium, along with serum and $100 \mu \mathrm{M}$ MSC, was added to the wells on the outside of the transwell over a period of 10 hours. The culture medium was aspirated from the inside of the transwell and the filter was wiped clean with a cotton swab. The outer side of the membrane was fixed in 1\% glutaraldehyde for 1 hour. After rinsing the glutaraldehyde solution, the filter was stained in hematoxylin for $10 \mathrm{~min}$. Filters were subsequently washed in water and the blue color was enhanced in saturated lithium carbonate solution for $5 \mathrm{~s}$. The cells migrating through the filter to the other side were examined microscopically under $\times 10$ magnification and representative areas were counted. The number of cells was averaged from three readings for each treatment.

\section{Statistical analysis}

All statistical analyses used SigmaPlot 8.0 software. Comparison of numerical data was achieved with a two-tailed unpaired $t$-test; $P<0.05$ was considered significant.

\section{Results}

Measurement of the TM6 hyperplastic growth spread in whole mounts of mammary fat pads 4 weeks after transplantation revealed that there was no differential effect between the two groups of mice fed with $0.1 \mathrm{ppm}$ Se and with 3 ppm Se (Table 1). However, by 12 weeks there was a significant decrease $(P<0.05)$ in the spread of TM6 growth in the $3 \mathrm{ppm}$ Se group in comparison with the growth in mammary fat pads of mice fed on the basal diet.

Table 1

Effect of Se-methylselenocysteine on proliferation and apoptosis in TM6-HOG transplanted into mammary fat pads

\begin{tabular}{|c|c|c|c|}
\hline \multirow[t]{2}{*}{ Parameter } & \multirow[t]{2}{*}{ Time of measurement (weeks) } & \multicolumn{2}{|c|}{ Se concentration (ppm) } \\
\hline & & 0.1 & 3 \\
\hline \multirow[t]{2}{*}{ Growth in fat pad } & 4 & $5.50 \pm 1.04$ & $5.25 \pm 0.85$ \\
\hline & 12 & $13.75 \pm 1.25$ & $8.13 \pm 1.88^{a}$ \\
\hline \multirow[t]{2}{*}{ BrdU labeling index } & 4 & $8.62 \pm 2.34$ & $7.00 \pm 0.64$ \\
\hline & 12 & $1.47 \pm 1.01$ & $1.27 \pm 0.24$ \\
\hline \multirow[t]{2}{*}{ Caspase-3 activity } & 4 & $0.08 \pm 0.01$ & $0.09 \pm 0.01$ \\
\hline & 12 & $0.06 \pm 0.01$ & $0.38 \pm 0.01^{b}$ \\
\hline
\end{tabular}

Growth in fat pad was measured as the length of spread between lymph nodes in millimeters; bromodeoxyuridine (BrdU) labeling index was expressed as the percentage cells positive; caspase- 3 activity was determined as $A_{405}$. Results are means $\pm \mathrm{SEM}$ for three or four observations. Student's $t$-test was performed to compare values between the $3 \mathrm{ppm}$ Se and $0.1 \mathrm{ppm}$ Se groups for each parameter. ${ }^{\mathrm{a}} P<0.05 ;{ }^{\mathrm{b}} P<0.0001$. 
Figure 1

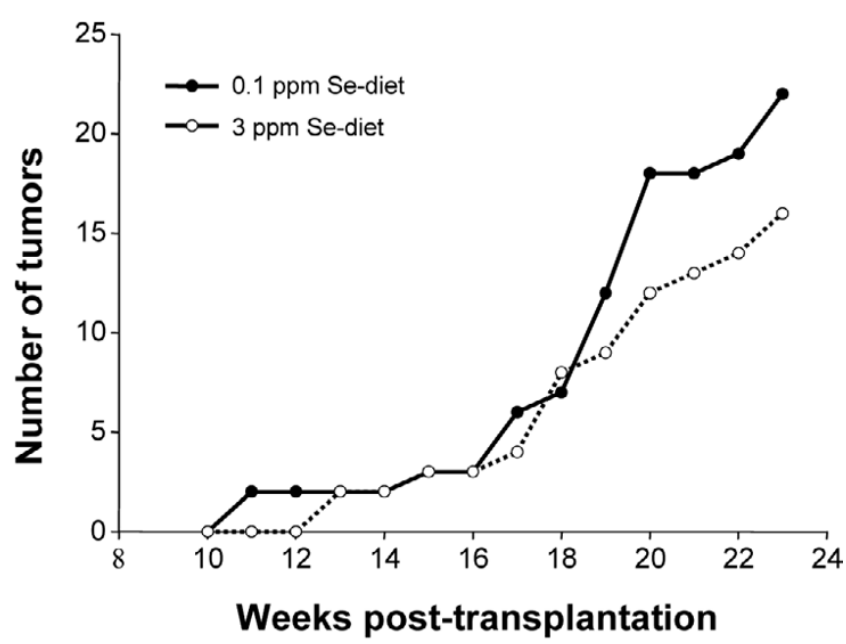

TM6 mouse mammary tumor incidence following supplementation with Se-methylselenocysteine (MSC). The latency period for tumor appearance in the $3 \mathrm{ppm}$ Se group was delayed by 2 weeks compared with the first tumor appearance in the $0.1 \mathrm{ppm}$ Se group animals. At the end of 23 weeks, $0.1 \mathrm{ppm}$ Se group had tumors in 22 of 26 mammary fat pads compared with tumors in 16 of 26 mammary fat pads in mice fed on the 3 ppm Se-diet.

The BrdU labeling index, indicative of proliferation in cells, is directly related to the number of cells in S phase. We found that 4 weeks after transplantation the labeling was high; it then decreased by 12 weeks. There was no significant difference between the 0.1 and $3 \mathrm{ppm}$ Se groups at either time point (Table 1). Furthermore, 12 weeks after transplantation, selenium-induced caspase-3 activity in the mammary fat pads of mice fed on $3 \mathrm{ppm}$ Se diet was elevated more than sixfold in comparison with that in mice fed with $0.1 \mathrm{ppm} \mathrm{Se}(P<0.0001)$ (Table 1).

The first appearance of palpable tumors was delayed by 2 weeks in the $3 \mathrm{ppm}$ Se group in comparison with mice fed on the $0.1 \mathrm{ppm}$ Se diet (Fig. 1). Twenty-three weeks after transplantation, all female Balb/c mice fed on the $0.1 \mathrm{ppm}$ Se diet developed mammary tumors, whereas only $77 \%$ of mice fed with $3 \mathrm{ppm}$ Se produced tumors in the same period. The total number of tumors in mice in the $0.1 \mathrm{ppm}$ Se group (22 of 26 fat pads) decreased to 16 of 26 fat pads in the $3 \mathrm{ppm}$ Se group $(P>0.05)$. However, the average tumor size in the $3 \mathrm{ppm}$ Se group $\left(0.69 \pm 0.19 \mathrm{~cm}^{2}\right)$ was smaller than that in the $0.1 \mathrm{ppm}$ Se group $(0.93 \pm 0.43$ $\mathrm{cm}^{2}$ ).

The cDNA array analysis of the tumors from both treatment groups revealed several differentially expressed genes. The $m$ Sim transcription factor was upregulated more than eightfold in the $3 \mathrm{ppm}$ Se group compared with the 0.1 ppm Se group (B2h; Fig. 2a). Genes upregulated in the 0.1 ppm Se group included prothymosin a (B12f; 1.4-fold
Figure 2

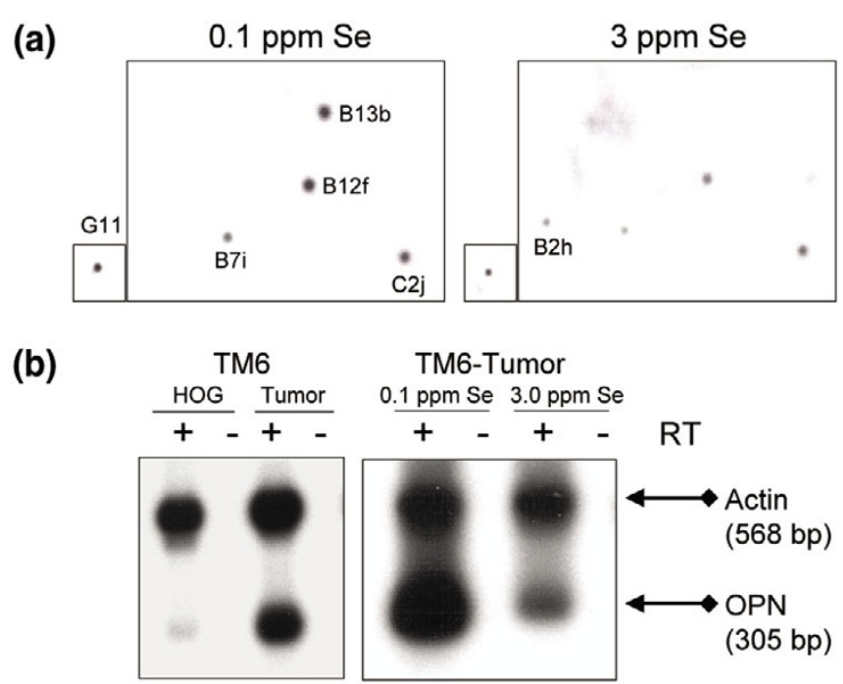

cDNA array analysis of mammary tumors and osteopontin gene expression. (a) The section of the Atlas ${ }^{\mathrm{TM}}$ Mouse 1.2 Array (Clontech, Chatsworth, CA) showing the differential expression of several genes in mammary fat pads transplanted with TM6-HOG and fed with 0.1 and 3 ppm Se in their diet. B2h, $m$ Sim transcription factor; B7i, YB1 DNAbinding protein; B12f, prothymosin $\alpha$; B13b, osteopontin (OPN); C2j, apolipoprotein $E ; \mathrm{G} 11$, ubiquitin (housekeeping gene for normalization). (b) Representative hybridization of reverse transcription-polymerase chain reaction (RT-PCR) bands from mammary fat pads of mice transplanted with TM6-HOG and fed with 0.1 and $3 \mathrm{ppm}$ Se in their diet that were probed with an OPN probe followed by a $\beta$-actin probe. The expression of OPN was 14-fold higher in the TM6 tumor than in TM6-HOG (left panel) and was decreased 3.85 -fold by the high selenium diet (right panel). The actin levels were similar, indicating equivalent input for RNA in the assay. The negative controls for the RT-PCR were reactions without reverse transcriptase $(-\mathrm{RT})$ during first-strand synthesis of cDNA.

increase; Fig. 2a), apolipoprotein $E$ (C2j; 1.45-fold increase; Fig. 2a), YB1 DNA-binding protein (B7i; 1.4-fold increase; Fig. 2a) and OPN (B13b; 14.3-fold increase; Fig. 2a). For the present study, we further analyzed the effects of MSC on OPN in vivo and in vitro.

OPN expression in the TM6 tumor was elevated more than 14-fold compared with its level in TM6-HOG tissue (Fig. $2 b$, left panel). TM6 tumors in the 3 ppm Se group demonstrated a markedly decreased expression of OPN (Fig. $2 b$, right panel) vis-à-vis those in the $0.1 \mathrm{ppm}$ Se group. The average OPN expression in a set of three TM6 tumors in the $3 \mathrm{ppm}$ Se group was $2.84( \pm 0.17)$-fold lower than that in the tumors from the control $(0.1 \mathrm{ppm} \mathrm{Se})$ group when normalized with $\beta$-actin expression.

In view of the observation that OPN is related to cell spread and motility [21], we examined the effect of Se on OPN expression levels and cell invasion in vitro. After stimulation with growth factors and serum, OPN expression in the TM6 tumor cells growing in vitro increased more than ninefold 
Figure 3

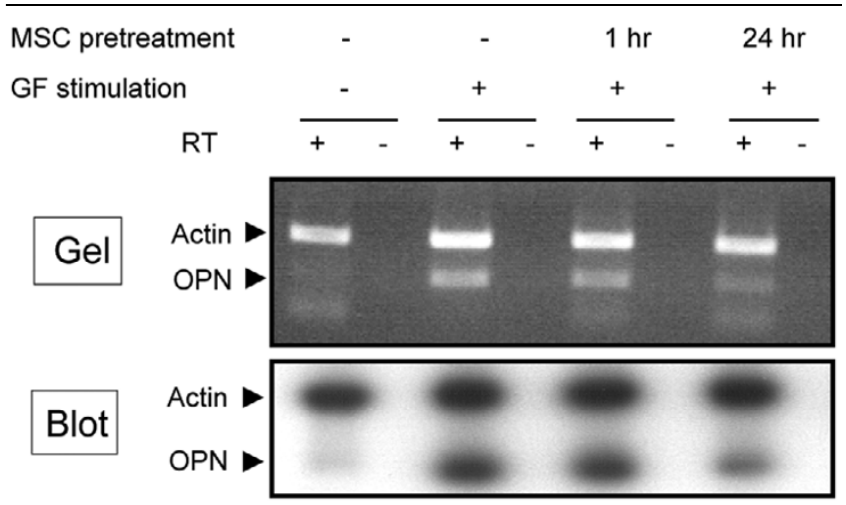

Osteopontin (OPN) gene expression in vitro. TM6 cells were starved for 24 hours before stimulation for 1 hour with growth factors (GF). A ninefold increase was noted in OPN expression within 1 hour of stimulation compared with the OPN level in starved cells. When the starved cells were treated with Se-methylselenocysteine (MSC) for either 1 hour or 24 hours before stimulation with GF, the expression of OPN was decreased 0.2-fold and 4.4-fold respectively compared with the 1hour-stimulated OPN level in the starved cells. The fold change was normalized with $\beta$-actin levels in the corresponding lanes.

compared with its level in the unstimulated TM6 cells (Fig. 3). A 24-hour treatment with $100 \mu \mathrm{M} \mathrm{MSC}$ followed by growth factor and serum stimulation downregulated OPN expression 4.4-fold compared with the OPN level in TM6 cells after 1 hour of stimulation with growth factor, as seen by RT-PCR bands and hybridized blots (Fig. 3 ).

Pretreatment with $100 \mu \mathrm{M}$ MSC for 24 hours significantly $(P<0.0001)$ inhibited TM6 cell migration in vitro compared with control untreated cells (Fig. 4). The earliest inhibition by MSC was observed after only 1 hour of pretreatment $(P<0.0001)$.

\section{Discussion}

MSC inhibits TM6 cell growth at the hyperplastic and tumor stages in the mouse mammary model. A significant decrease in growth spread of TM6 hyperplasia in mouse mammary fat pads at 12 weeks after transplantation might have been due to elevated caspase-3 activity in the $3 \mathrm{ppm}$ Se group. However, this growth inhibition was not associated with decreased BrdU incorporation. The lack of suppression of proliferation is indicative of a possible delay of mammary tumorigenesis by pathways that might not involve cell growth inhibition as a primary response, as also suggested by another report [4]. To our knowledge, the present study shows for the first time that selenium can activate caspase-3 in vivo. This finding is supported by other reports demonstrating apoptosis in mammary tumors in vivo $[22,23]$ as well as in the surrounding vasculature [24]. Further work is needed to understand the mechanism(s) by which MSC induces cell death in pre-neoplastic
Figure 4

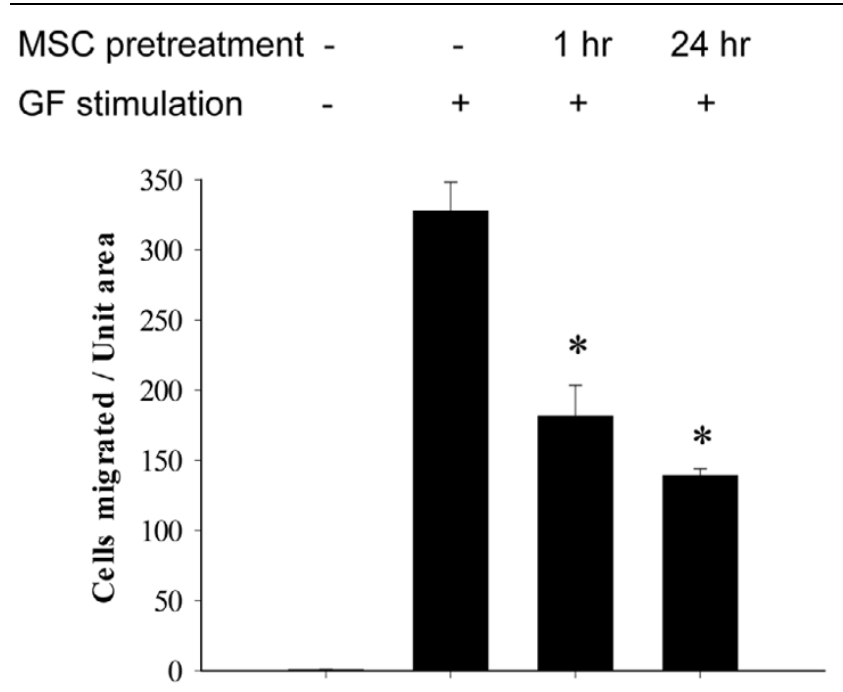

MSC inhibits TM6 cell migration in vitro. Pretreatment of TM6 cells with Se-methylselenocysteine (MSC) for 1 hour and 24 hours before stimulation with growth factors (GF) and serum decreased the numbers of cells migrating by $44.6 \%$ and $57.6 \%$, respectively, to the other end of the membrane in a transwell migration assay. Bar graphs represent the mean of four counts from each of the three separate wells. Error bars are SEM. The inhibition in migration was statistically significant at $P<$ 0.0001 for both pretreatments compared with controls. Only one or two cells were able to migrate in the absence of growth factors.

lesions in vivo, particularly the crosstalk between the signaling molecules of the proliferative and apoptotic pathways.

The first appearance of palpable tumors in the present study was delayed by 2 weeks in the 3 ppm Se group in comparison with mice fed on the $0.1 \mathrm{ppm}$ Se diet. Furthermore, there was a $23 \%$ inhibition in tumor incidence in the $3 \mathrm{ppm}$ Se group. These data are in agreement with previous studies $[25,26]$ showing that later stages of mouse mammary tumorigenesis (pre-neoplastic to neoplastic transformation of tumor growth) are not as sensitive to selenium-mediated inhibition as the early stages (expression of mammary pre-neoplastic lesions). The degree of inhibition in tumor formation by MSC in our mouse model was modest compared with that demonstrated in chemical carcinogen-induced rat mammary tumor models $[3,4]$. This difference might be related to MSC-mediated inhibition at initiation (carcinogen metabolism and DNA adduct formation) and promotion (proliferation and apoptosis) stages and/or the species of animals examined.

The mammary tumors in the $3 \mathrm{ppm}$ Se group were smaller than those of the $0.1 \mathrm{ppm}$ Se group, and the comparative cDNA array analysis of these tumors revealed several differentially expressed genes. To our knowledge, this is the first report of OPN expression being downregulated by any selenium compound. In the present study, the TM6-HOG tissue was compared with that of the TM6 tumor for OPN 
expression, which was elevated more than 14 -fold. This difference could not be attributed to tissue heterogeneity in the TM6 outgrowth, because mammary epithelial cells comprise the vast majority of the source of RNA (more than $60 \%$ ). OPN is expressed at higher levels in various transformed cell lines than in their non-tumorigenic cell counterparts [17]. It has been associated with greater malignancy in breast cancer but its functional role in this process is poorly understood. OPN transcripts can be detected in both invasive and in situ carcinoma components of human breast cancer. However, the transcripts are not detected in surrounding stromal cells or in peritumoral macrophages [27]. The fact that treatment with $3 \mathrm{ppm}$ Se in the form of MSC decreases OPN expression in vivo might be contributing to the smaller size of tumors observed in our study. The contribution that OPN makes to the development of malignancy remains obscure. Possibly OPN promotes the development of a malignancy by stimulating cellular signal transduction pathways through the $\alpha_{v} \beta_{3}$ integrin [28]. Further experimentation will be required to determine whether the inhibition of mammary tumors by selenium involves this integrin. An earlier report suggested that the ability to produce OPN does indeed contribute to the metastatic potential of cells [29]. We have also observed that the OPN expression in a TM40D mouse mammary model that has the potential to form metastasis is significantly lowered by a 3 ppm Se diet (Emmanual Unni, Frances S Kittrell and Raghu Sinha, unpublished data).

Both the toxicity and the chemopreventive efficacy of a selenium compound are mainly expressed as a function of its dose and the chemical form [30]. MSC is a stable selenoamino acid that is capable of generating methylselenol endogenously through the action of $\beta$-lyase or related lyases [31]. Because the cells in culture have low levels of $\beta$-lyase, leading to inefficient conversion of MSC to methylselenol $[32,33]$, we used a higher dose $(100 \mu \mathrm{M})$ of MSC for the cell migration experiment. In cell culture experiments, doses of 50-100 $\mu \mathrm{M}$ MSC have been shown to inhibit mouse mammary epithelial tumor cell growth effectively $[4,8]$. Our data demonstrating a decline of OPN expression after 24 hours of treatment with MSC is suggestive of a role for selenium in the attachment and migration of TM 6 cells in vitro. Future experiments will examine a range of MSC concentrations, including the physiological dose of $5 \mu \mathrm{M}$.

Considerable evidence indicates that $\alpha_{v} \beta_{3}$ integrin is important in cell motility and can mediate attachment to various adhesive substrates [34]. We have shown earlier that selenium alters the gene expression of integrin- $\beta$ and laminin receptor-1 in TM6 cells [20]. To elucidate whether selenium is important in $\alpha_{v} \beta_{3}$ integrin-mediated migration inhibitions of TM6 cells will need further experimentation.
In summary, these studies show that MSC can affect TM6 cell growth at the preneoplastic and malignant growth stages. One mediator is a lower expression of OPN and the other is activated caspase-3. Further experimentation is required to define the role of OPN in the inhibition of mammary tumorigenesis by selenium.

\section{Conclusions}

We have analyzed OPN expression in TM6 tumors of mice fed on a 0.1 or 3 ppm Se diet. Lowered levels of OPN in tumors of mice fed with high selenium in their diet suggest that this gene might have a role in the selenium-induced inhibition of mammary growth. Similarly, lowered OPN expression and decreased migration of TM6 tumor cells after treatment with MSC indicate a possible role of OPN in selenium-induced inhibition in vitro. Furthermore, caspase- 3 activation in fat pads of mice fed on a high selenium diet might contribute to the decreased growth spread in the mammary.

\section{Competing interests}

None declared.

\section{Acknowledgements}

We thank Daniel Medina, Professor of Cellular and Molecular Biology, Baylor College of Medicine, Houston, TX, and Karam El-Bayoumy, Institute for Cancer Prevention, Valhalla, NY, for review of this manuscript. We also thank llse Hoffman for editing the manuscript. A US Army Medical Research and Materiel Command Breast Cancer Research Grant (DAMD17-1-99-9076) to RS supported this work.

\section{References}

1. Clark LC, Combs GF Jr, Turnbull BW, Slate EH, Chalker DK, Chow J, Davis LS, Glover RA, Graham GF, Gross EG et al.: Effects of selenium supplementation for cancer prevention in patients with carcinoma of the skin. A randomized controlled trial. Nutritional Prevention of Cancer Study Group. JAMA 1996, 276:1957-1963.

2. Ip C, Birringer M, Block E, Kotrebai M, Tyson JF, Uden PC, Lisk DJ: Chemical speciation influences comparative activity of selenium-enriched garlic and yeast in mammary cancer prevention. J Agric Food Chem 2000, 48:2062-2070.

3. Ip C, Lisk DJ, Thompson HJ: Selenium-enriched garlic inhibits the early stage but not the late stage of mammary carcinogenesis. Carcinogenesis 1996, 17:1979-1982.

4. Lu J, Pei H, Ip C, Lisk DJ, Ganther H, Thompson HJ: Effect on an aqueous extract of selenium-enriched garlic on in vitro markers and in vivo efficacy in cancer prevention. Carcinogenesis 1996, 17:1903-1907.

5. Ip C, Thompson HJ, Ganther HE: Selenium modulation of cell proliferation and cell cycle biomarkers in normal and premalignant cells of the rat mammary gland. Cancer Epidemiol Biomarkers Prev 2000, 9:49-54.

6. Ip C, Thompson HJ, Zhu Z, Ganther HE: In vitro and in vivo studies of methylseleninic acid: evidence that a monomethylated selenium metabolite is critical for cancer chemoprevention. Cancer Res 2000, 60:2882-2886.

7. Sinha R, Kiley SC, Lu JX, Thompson HJ, Moraes R, Jaken S, Medina D: Effects of methylselenocysteine on PKC activity, cdk2 phosphorylation and gadd gene expression in synchronized mouse mammary epithelial tumor cells. Cancer Lett 1999, 146:135-145.

8. Sinha R, Medina D: Inhibition of cdk2 kinase activity by methylselenocysteine in synchronized mouse mammary epithelial tumor cells. Carcinogenesis 1997, 18:1541-1547. 
9. Unni E, Singh U, Ganther HE, Sinha R: Se-methylselenocysteine activates caspase- 3 in mouse mammary epithelial tumor cells in vitro. Biofactors 2001, 14:169-177.

10. Sinha R, Unni E, Singh U, Koul D, Yung WKA: Se-methylselenocysteine inhibits phosphatidylinositol 3-kinase pathway in mouse mammary epithelial tumor cells [abstract]. Proc Am Assoc Cancer Res 2003, 44:s887.

11. Tsitsiloni OE, Stiakakis J, Koutselinis A, Gogas J, Markopoulos C, Yialouris P, Bekris S, Panoussopoulos D, Kiortsis V, Voelter W et al:: Expression of alpha-thymosins in human tissues in normal and abnormal growth. Proc Natl Acad Sci USA 1993, 90:9504-9507.

12. Bargou RC, Jurchott $\mathrm{K}$, Wagener $\mathrm{C}$, Bergmann $\mathrm{S}$, Metzner $\mathrm{S}$, Bommert K, Mapara MY, Winzer KJ, Dietel M, Dorken B et al.: Nuclear localization and increased levels of transcription factor YB-1 in primary human breast cancers are associated with intrinsic MDR1 gene expression. Nat Med 1997, 3:447-450.

13. Janz $M$, Harbeck N, Dettmar $P$, Berger U, Schmidt A, Jurchott $K$, Schmitt M, Royer HD: Y-box factor YB-1 predicts drug resistance and patient outcome in breast cancer independent of clinically relevant tumor biologic factors HER2, uPA and PAI-1. Int J Cancer 2002, 97:278-282.

14. Ema M, Suzuki M, Morita M, Hirose K, Sogawa K, Matsuda $Y$, Gotoh O, Saijoh Y, Fujii $\mathrm{H}$, Hamada $\mathrm{H}$ et al:: cDNA cloning of a murine homologue of Drosophila single-minded, its mRNA expression in mouse development, and chromosome localization. Biochem Biophys Res Commun 1996, 218:588-594.

15. Mahley RW: Apolipoprotein E: cholesterol transport protein with expanding role in cell biology. Science 1988, 240:622-630.

16. Denhardt DT, Guo X: Osteopontin: a protein with diverse functions. FASEB J 1993, 7:1475-1482.

17. Senger DR, Perruzzi CA, Papadopoulos A: Elevated expression of secreted phosphoprotein I (osteopontin, 2ar) as a consequence of neoplastic transformation. Anticancer Res 1989, 9:1291-1299.

18. Medina D: Preneoplastic lesions in mouse mammary tumorigenesis. In Methods in Cancer Research Edited by: Busch $\mathrm{H}$. New York: Academic Press; 1973:3-53.

19. Said TK, Bonnette S, Medina D: Immortal, non-tumourigenic mouse mammary outgrowths express high levels of cyclin B1 and activation of cyclin B1/cdc2 kinase. Cell Prolif 1996, 29:623-639.

20. Sinha R, Unni E, Ganther HE, Medina D: Methylseleninic acid, a potent growth inhibitor of synchronized mouse mammary epithelial tumor cells in vitro. Biochem Pharmacol 2001, 61:311-317.

21. Katagiri YU, Sleeman J, Fujii $H$, Herrlich $P$, Hotta $H$, Tanaka $K$, Chikuma S, Yagita $\mathrm{H}$, Okumura $\mathrm{K}$, Murakami M et al:: CD44 variants but not CD44s cooperate with $\beta_{1}$-containing integrins to permit cells to bind to osteopontin independently of arginine-glycine-aspartic acid, thereby stimulating cell motility and chemotaxis. Cancer Res 1999, 59:219-226.

22. Ip C, Dong Y: Methylselenocysteine modulates proliferation and apoptosis biomarkers in premalignant lesions of the rat mammary gland. Anticancer Res 2001, 21:863-867.

23. El-Bayoumy K, Narayanan BA, Desai DH, Narayanan NK, Pittman B, Amin SG, Schwartz J, Nixon DW: Elucidation of molecular targets of mammary cancer chemoprevention in the rat by organoselenium compounds using cDNA microarray. Carcinogenesis 2003, 24:1505-1514.

24. Jiang $\mathrm{C}$, Jiang $\mathrm{W}$, Ip $\mathrm{C}$, Ganther $\mathrm{H}$, Lu J: Selenium-induced inhibition of angiogenesis in mammary cancer at chemopreventive levels of intake. Mol Carcinog 1999, 26:213-225.

25. Medina D, Lane HW: Stage specificity of selenium-mediated inhibition of mouse mammary tumorigenesis. Biol Trace Element Res 1983, 5:297-306.

26. Lane HW, Medina D, Wolfe LG: Proposed mechanisms for selenium-inhibition of mammary tumorigenesis. In Vivo 1989, 3:151-160.

27. Sharp JA, Sung V, Slavin J, Thompson EW, Henderson MA: Tumor cells are the source of osteopontin and bone sialoprotein expression in human breast cancer. Lab Invest 1999, 79:869-877.

28. Zheng DQ, Woodard AS, Tallini G, Languino LR: Substrate specificity of $\alpha_{v} \beta_{3}$ integrin-mediated cell migration and phosphati- dylinositol 3-kinase/AKT pathway activation. I Biol Chem 2000, 275:24565-24574.

29. Gardner HA, Berse B, Senger DR: Specific reduction in osteopontin synthesis by antisense RNA inhibits the tumorigenicity of transformed Rat1 fibroblasts. Oncogene 1994, 9:2321-2326.

30. Ip C: Lessons from basic research in selenium and cancer prevention. J Nutr 1998, 128:1845-1854.

31. Ip C, Ganther HE: Comparison of selenium and sulfur analogs in cancer prevention. Carcinogenesis 1992, 13:1167-1170.

32. Wang Z, Jiang C, Lu J: Induction of caspase-mediated apoptosis and cell-cycle $\mathrm{G} 1$ arrest by selenium metabolite methylselenol. Mol Carcinog 2002, 34:113-120.

33. Zhu Z, Jiang W, Ganther HE, Ip C, Thompson HJ: In vitro effects of Se-allylselenocysteine and Se-propylselenocysteine on cell growth, DNA integrity, and apoptosis. Biochem Pharmacol 2000, 60:1467-1473.

34. Felding-Habermann B, Ruggeri ZM, Cheresh DA: Distinct biological consequences of integrin $\alpha_{\mathrm{v}} \beta_{3}$-mediated melanoma cel adhesion to fibrinogen and its plasmic fragments. J Biol Chem 1992, 267:5070-5077. 